\title{
Peripheral Immune Cell Counts and Advanced Imaging as Biomarkers of Stroke Outcome
}

\author{
Heather Pagram ${ }^{a} \quad$ Andrew Bivard ${ }^{a} \quad$ Lisa F. Lincz ${ }^{b} \quad$ Christopher Levi ${ }^{a}$ \\ aDepartment of Neurology, John Hunter Hospital, University of Newcastle, \\ New Lambton Heights, N.S.W., and b Hunter Haematology Research Group, \\ Calvary Mater Newcastle Hospital, Waratah, N.S.W., Australia
}

Key Words

Neutrophils $\cdot$ Lymphocytes $\cdot$ Ischemic stroke $\cdot$ Cell count

\begin{abstract}
Introduction: Circulating neutrophil and lymphocyte levels may be modifiable outcome predictors of ischemic stroke. We sought to compare these immune cell parameters with advanced imaging assessment and the 90-day clinical outcome. Methods: We used a retrospectively collected cohort of consecutive ischemic stroke patients presenting within $4.5 \mathrm{~h}$ of symptom onset who had acute CT perfusion and routine blood collection before treatment with intravenous thrombolysis and 24-hour MRI scanning at the John Hunter Hospital. Full blood counts were performed acutely at $24 \mathrm{~h}$ and 7 days. Patient outcomes were assed at 90 days after stroke with the modified Rankin Scale (mRS). Results: Overall, 142 patients were assessed during the study period. Patients with a poor outcome (mRS 3-6) had increased neutrophils (44\% increase, $p=0.016)$, decreased lymphocytes ( $7 \%$ decrease, $p=0.491$ ) and an increased lymphocyte-to-neutrophil ratio $(196 \%$ increase, $p<0.001)$. Patients with good outcomes (mRS 0-2) did not have significant changes in their full blood counts. There was no relationship between the neutrophil count at $24 \mathrm{~h}$ and penumbral volume $\left(r^{2}=0.217, p=\right.$ $0.212)$, reperfusion $\left(r^{2}=0.111, p=0.085\right)$, or core growth $\left(r^{2}=0.297, p=0.107\right)$. A backward multivariate analysis containing the 24 -hour core volume and 24 -hour neutrophil count was strongly related to the 3 -month outcome $\left(r^{2}=0.477\right.$, area under the curve $\left.=0.902, p<0.001\right)$. Conclusions: Peripheral neutrophils have potential as a biomarker of outcome when used in conjunction with advanced imaging. Peripherally measured neutrophil counts change significantly over time after stroke and may be potential targets for immunomodulatory therapy in patients with a severe stroke or a large infarct volume.




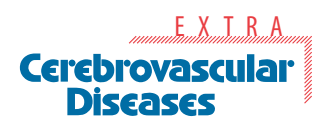

\begin{tabular}{l|l}
\hline Cerebrovasc Dis Extra 2016;6:120-128 \\
\hline DOI: 10.1159/000450620 & $\begin{array}{l}\text { @ 2016 The Author(s). Published by S. Karger AG, Basel } \\
\text { www.karger.com/cee }\end{array}$ \\
\hline
\end{tabular}

Pagram et al.: Peripheral Immune Cell Counts and Advanced Imaging as Biomarkers of Stroke Outcome

\section{Introduction}

Neutrophils may be a potential therapeutic target in ischemic stroke. They are the fastest and most prolific leucocyte responders to brain ischemia, contributing to the blood-brain barrier disruption, cerebral edema and brain injury. Neutrophilia contributes to an increase in proinflammatory cytokines, chemokines, proteases and reactive oxygen species (ROS) within the central nervous system (CNS) [1], all of which contribute to cell death pathways within the ischemic penumbra [2]. Neutrophils also negatively alter the function of the microvasculature, thus contributing to ischemia [3], and increased counts have been associated with worse outcomes at hospital discharge [4]. However, neutrophils are essential for the recruitment of monocytes and macrophages to the necrotic infarction site [5] and help to prevent the onset of stroke-associated infections, which occur in $30-40 \%$ of all stroke patients and result in significantly increased rates of mortality [6]. Thus far, human drug trials aiming to prevent potentially harmful neutrophil adhesion and infiltration into the brain parenchyma subacutely after stroke have failed. Two trials have proved futile and have been halted early $[7,8]$ while another has caused harm [9] despite preclinical studies, showing reduced infarction sizes [10] and improved functional outcome [11] as a result of neutrophil blockading up to $48 \mathrm{~h}$ after experimental stroke. This discrepancy may be due to the inherent physiological differences in metabolism and cerebral vasculature between rodents and higher mammals [12]. However, human trials have not had stringent patient selection criteria in terms of stroke subtype nor severity when compared to the standardization of laboratory models. Furthermore, reperfusion therapies were rarely used in earlier trials $[13,14]$. Potentially, a combination of biological and advanced imaging biomarkers is required to select patients who will respond well to immunomodulatory therapy during the subacute phase after stroke. We hypothesized that thrombolyzed patients with 'good' and 'poor' outcomes at 90 days after stroke would show differential immune cell counts after ischemic stroke and that this would be related to stroke lesion pathophysiology. We aimed to assess the acute, 24-hour and 1-week peripheral cell counts in patients admitted with an acute ischemic stroke who underwent advanced imaging prior to intravenous thrombolysis therapy.

\section{Methods}

Patients with baseline, 24-hour, and 90-day clinical and imaging data from the John Hunter Hospital (JHH), New Lambton Heights, N.S.W., Australia, were prospectively collected over a 5-year period (2009-2013). All patients presenting within $4.5 \mathrm{~h}$ of symptom onset were rapidly screened on arrival in the emergency department by a stroke neurologist or stroke fellow. If they had an acute neurological deficit deemed significant enough to warrant consideration for thrombolysis National Institutes of Health Stroke Scale (NIHSS; cutoff not used), they routinely underwent CT perfusion (CTP) and CT angiography after exclusion of intracranial hemorrhage on noncontrast CT. Endovascular reperfusion techniques were not available at JHH during the study period. Follow-up imaging with MRI at $24 \mathrm{~h}$ after stroke was also routine unless the patient was MR incompatible, in which case repeat multimodal CT was performed. Clinical stroke severity was assessed immediately prior to the acute and 24-hour imaging using the NIHSS. At 90 days after stroke onset, patient disability was assessed by the modified Rankin scale (mRS) by staff not involved in the patient's acute care. All data collection was approved by the Hunter New England Health Research Committee, and all patients gave informed consent for their data to be used in this study.

Emergency department admission and subsequent stroke unit care full blood counts were obtained retrospectively from the electronic medical record. Cell counts were obtained 
Pagram et al.: Peripheral Immune Cell Counts and Advanced Imaging as Biomarkers of Stroke Outcome

at the following time points: (1) acutely, before treatment; (2) after treatment and within $24 \mathrm{~h}$ of stroke onset, and (3) 7 days after stroke onset. At each time point, the neutrophil and lymphocyte counts were recorded. Patients were excluded if the pathology results indicated some doubt about the quality of a blood sample.

\section{Imaging}

Whole-brain CTP and CT angiography were acquired in a single acquisition simultaneously. Subjects were scanned using a Toshiba Aquilion One 320-slice CT scanner (Toshiba Medical Systems, Tokyo, Japan). A total of 19 acquisitions occurred in 60 s. Forty milliliters of contrast agent (Ultravist 370; Bayer HealthCare, Berlin, Germany) were injected at $6 \mathrm{ml} / \mathrm{s}$, followed by $30 \mathrm{ml}$ of saline.

All patients underwent MRI at $24 \mathrm{~h}$ after CTP, using Avanto 1.5T or Vario 3T scanners (Siemens, Munich, Germany). MRI sequences included T1-weighted imaging, T2-weighted imaging, diffusion-weighted imaging, a gradient echo sequence and flow-attenuated inversion recovery.

\section{Image Postprocessing}

All perfusion imaging was postprocessed on commercial software MIStar (Apollo Medical Imaging Technology, Melbourne, Vic., Australia). Acute perfusion imaging was processed using single-value deconvolution with delay and dispersion correction [15]. An arterial input function and venous outflow function was semiautomatically selected from the nonstroke hemisphere middle cerebral artery/anterior cerebral artery and sagittal sinus, respectively. Previously validated thresholds were applied in order to measure the volume of the acute perfusion lesion (delay time $>3 \mathrm{~s}$ ) and acute ischemic core (relative cerebral blood flow, $<30 \%$ ) [16]. Penumbral volume was calculated from the volume of the perfusion lesion minus the volume of the ischemic core (relative cerebral blood flow threshold $<30 \%$ within the delay time $>3 \mathrm{~s}$ lesion). Mismatch was defined as the ratio of the perfusion lesion volume to the acute ischemic core volume.

\section{Statistical Analysis}

Statistical analysis was performed using IBM SPSS Statistics (version 22; IBM Corp, Armonk, N.Y., USA). In this cohort, we dichotomized mRS, defining a good outcome as mRS 0-2 and a poor outcome as mRS 3-6. First, descriptive statistics were obtained for the population age and imaging parameters. An independent samples t test was conducted between the neutrophil and lymphocyte counts and the neutrophil-to-lymphocyte ratio (NLR) of the two subgroups (good outcome vs. poor outcome) at each of the data collection time points (acute, $24 \mathrm{~h}$ and 1 week after stroke). Next, bivariate correlations between the following variables (acute core volume, 24-hour core volume, core growth, penumbral volume, age, neutrophil and lymphocyte counts and NLR) were conducted. Those variables that yielded significant results then underwent univariate regression. Backward multivariate regression was subsequently used to test whether immune measures and advanced imaging derived parameters that appeared significant in univariate regression could be used in a predictive model of clinical stroke outcomes. Odds ratios were generated based on standard clinical cutoff values for neutrophils (normal: $<7.7 .10^{9}$ cells/l of blood; high: $>7.6 .10^{9}$ cells $/$ l of blood). Binary logistic regression was used to generate a single probability value from significant predictors. Lastly, a receiver operating characteristic curve analysis was used to generate an area under the curve (AUC) to identify the sensitivity and specificity of the predictive efficacy of the model. 


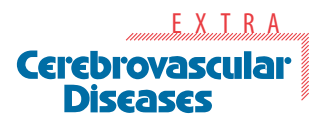

\begin{tabular}{l|l}
\hline Cerebrovasc Dis Extra 2016;6:120-128 \\
\hline DOI: 10.1159/000450620 & $\begin{array}{l}\text { C } 2016 \text { The Author(s). Published by S. Karger AG, Basel } \\
\text { www.karger.com/cee }\end{array}$ \\
\hline
\end{tabular}

Pagram et al.: Peripheral Immune Cell Counts and Advanced Imaging as Biomarkers of Stroke Outcome

Table 1. Population imaging and demographical data at baseline and $24 \mathrm{~h}$

\begin{tabular}{llll}
\hline & Good outcome $(\mathrm{mRS} \leq 2)$ & Poor outcome $(\mathrm{mRS} \geq 3)$ & $\mathrm{p}$ \\
\hline Total patients & 82 & 59 & 0.391 \\
\hline $\begin{array}{l}\text { Age, years } \\
\quad \text { Range }\end{array}$ & $26-95$ & $31-89$ & \\
$\quad$ Mean (median); SD & $73(73) ; 11$ & $76(79) ; 10$ & 0.018 \\
\hline $\begin{array}{l}\text { NIHSS (acute) } \\
\quad \text { Range }\end{array}$ & $2-23$ & $7-32$ & \\
$\quad$ Mean (median); SD & $12(12) ; 4$ & $17(18) ; 4$ & 0.192 \\
\hline $\begin{array}{l}\text { Glucose (acute draw), mM } \\
\quad \text { Range }\end{array}$ & $4.6-12.6$ & & $<0.001$ \\
$\quad$ Mean (median); SD & $6.45(5.90) ; 1.76$ & $7.9(6.1) ; 4.9$ & \\
\hline Acute core volume, $\mathrm{ml}{ }^{3}$ & & & 0.077 \\
$\quad$ Range & $0-58$ & $28-176$ & \\
$\quad$ Mean (median); SD & $19(59) ; 53$ & $56(53) ; 40$ & \\
\hline Acute penumbral volume, $\mathrm{ml}^{3}$ & & & \\
$\quad$ Range & $0-186$ & $83(82) ; 48$ & \\
$\quad$ Mean (median); SD & $58(48) ; 48$ & &
\end{tabular}

\section{Results}

During the study period, 166 patients were admitted to the JHH stroke unit, with 142 patients having sufficient recorded data, and were included in the analysis ( 21 were excluded due to incomplete or erroneous blood testing, and 3 patients because of poor quality imaging); baseline demographic and clinical outcomes are shown in table 1. Compared to those with a good outcome, patients with a poor outcome had statistically significantly more severe strokes (NIHSS scores: $12 \pm 4$ vs. $17 \pm 4, \mathrm{p}<0.001$ ). Patients who would go on to have a good or poor outcome could not be predicted by acute levels of neutrophils (5.4 vs. $5.9, p=0.348$ ), lymphocytes (1.8 vs. $1.7, \mathrm{p}=0.846$ ) or NLR ( 3.7 vs. $4.9, \mathrm{p}=0.098$ ) as measured in the first 4.5 $\mathrm{h}$ after stroke onset and prior to thrombolysis treatment.

\section{Changes in Peripheral Immune Cell Counts after Stroke}

Patients with a poor outcome had a 44\% increase in neutrophils $(\mathrm{p}=0.016)$ and a concomitant $7 \%$ decrease in lymphocytes $(\mathrm{p}=0.491)$, resulting in a $196 \%$ increase $(\mathrm{p}<$ 0.001 ) in NLR (table 2). In contrast, patients with a good outcome had no significant change in neutrophils ( $p=0.187)$, lymphocytes $(p=0.316)$ or overall NLR $(p=0.057)$ within the same time period. The observed increase in neutrophils and NLR was significantly greater in patients with poor outcomes compared to those with good outcomes $(\mathrm{p}<0.001)$.

The peripheral neutrophilia in patients who would have a poor outcome at 90 days (mRS 3-6) persisted from the acute measurement to the 1 -week measurement $(72 \%$ increase, $\mathrm{p}<$ 0.001 ) compared to patients who would have a good outcome (mRS 0-2). Again, these parameters remained steady in patients who would have a good clinical outcome, with no significant change in neutrophils ( $p=0.297)$, lymphocytes $(p=0.384)$ or overall NLR $(p=0.068)$ within the same time period. 

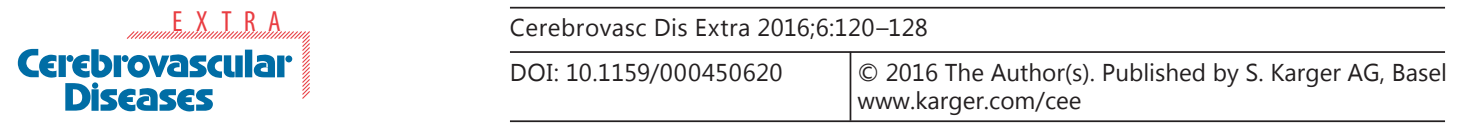

Pagram et al.: Peripheral Immune Cell Counts and Advanced Imaging as Biomarkers of Stroke Outcome

Table 2. A comparison of neutrophils, lymphocytes and NLR between patients with a good (mRS $0-2$ ) and a poor outcome

\begin{tabular}{|c|c|c|c|c|c|}
\hline & $\begin{array}{l}\text { Acute, } \\
\text { mean } \pm \text { SD }\end{array}$ & $\begin{array}{l}24 \mathrm{~h}, \\
\text { mean } \pm \mathrm{SD}\end{array}$ & $\begin{array}{l}\text { p acute vs. } \\
24 \mathrm{~h}\end{array}$ & $\%$ change & $\begin{array}{l}\text { p good vs. } \\
\text { poor }\end{array}$ \\
\hline Neutrophils, $\times 10^{9} / \mathrm{l}$ & $5.88 \pm 2.5$ & $7.96 \pm 3.8$ & $<0.001$ & & \\
\hline Good outcome & $5.43 \pm 2.1$ & $6.18 \pm 3.1$ & 0.187 & 28 & $<0.001$ \\
\hline Poor outcome & $5.89 \pm 2.7$ & $9.69 \pm 4.2$ & $<0.001$ & 44 & \\
\hline Lymphocytes, $\times 10^{9} / 1$ & $1.82 \pm 0.8$ & $1.46 \pm 0.7$ & 0.247 & & \\
\hline Good outcome & $1.85 \pm 0.7$ & $1.46 \pm 0.5$ & 0.316 & 15 & 0.065 \\
\hline Poor outcome & $1.66 \pm 0.8$ & $1.48 \pm 0.8$ & 0.225 & 7 & \\
\hline NLR & $4.2 \pm 1.5$ & $6.8 \pm 3.8$ & $<0.001$ & & \\
\hline Good outcome & $3.7 \pm 1.4$ & $5.4 \pm 2.5$ & 0.057 & 84 & $<0.001$ \\
\hline Poor outcome & $4.9 \pm 2.2$ & $9.3 \pm 5.6$ & $<0.001$ & 196 & \\
\hline
\end{tabular}

Advanced Imaging and Peripheral Immune Cell Counts as Predictors of Outcome

In both bivariate correlation and univariate logistic regression, the neutrophil count at $24 \mathrm{~h}$ correlated with the 24-hour core volume (Pearson correlation, $\mathrm{PC}=0.348, \mathrm{r}^{2}=0.321$; $\mathrm{p}=0.002 ; \mathrm{n}=77)$. There was no relationship between the neutrophil count at $24 \mathrm{~h}$ and penumbral volume $\left(r^{2}=0.217, p=0.212\right)$, reperfusion $\left(r^{2}=0.111, p=0.085\right)$, age $\left(r^{2}=0.197\right.$, $\mathrm{p}=0.960)$ nor core growth $(\mathrm{r}=0.297, \mathrm{p}=0.107)$. A backward multivariate analysis containing the 24-hour core volume and 24-hour neutrophil count was strongly related to the 3-month outcome $\left(r^{2}=0.477\right.$, AUC $=0.902, p<0.001$, fig. 1$)$.

At 7 days after ischemia, neutrophils remained significantly related to the 24-hour core volume ( $\mathrm{PC}=0.285, \mathrm{r}^{2}=0.285 ; \mathrm{p}=0.013$ ). An increased 7-day neutrophil count was also related to an increased incidence of successful reperfusion $\left(\mathrm{PC}=0.338, \mathrm{r}^{2}=0.114\right.$, $\mathrm{p}=0.002$ ). A backward multivariate analysis containing the 24 -hour core volume and 7 -day neutrophil count was strongly related to the 3-month outcome $\left(\mathrm{r}^{2}=0.548\right.$, AUC $0.936, \mathrm{p}<0.001$, fig. 2).

\section{Discussion}

We observed significant relationships between peripheral neutrophil counts, stroke outcome and advanced imaging parameters. These relationships were apparent at $24 \mathrm{~h}$ and 7 days after stroke, but not acutely. Our results suggest that neutrophil count may be a prognostic marker independent of stroke severity; however, a confounding effect of stroke severity or other unmeasured variables cannot be ruled out. Notably, neutrophil counts were only weakly correlated to imaging parameters, and both remained independent predictors in our multivariate model, accounting for nearly $50 \%$ of the variability in stroke outcomes. Thus, these two variables most likely represent different biological mechanisms in the pathophysiology of ischemia, which together form a strong predictive model of outcome. Consequently, neutrophil count in particular could be used as an easily measurable biomarker of the longterm outcome and a promising therapeutic target in severe stroke.

Notably, there was no association between the outcome and admission neutrophil count, nor was there significant difference in cell counts between the good- and poor-outcome groups at this early time point. At $24 \mathrm{~h}$ and 7 days, however, the poor-outcome group had developed significantly higher neutrophil counts. It is possible that the peripheral neutrophil response is triggered by the severity of an acute ischemic lesion, with larger lesion volumes 


\section{Cerebrovascular. \\ Diseases}

Fig. 1. Predictive efficacy of the 7day neutrophil model. Good outcome at 90 days using the 7-day neutrophil count and 24-hour core volume. $\mathrm{ROC}=$ Receiver operating characteristic, AUC = $0.936, \mathrm{SE}=0.026,95 \% \mathrm{CI}: 0.885-$ $0.987, \mathrm{p}<0.001$.

Fig. 2. Predictive efficacy of the 24-hour neutrophil model. Good outcome at 90 days using the 24hour neutrophil count and 24hour core volume. $\mathrm{ROC}=$ Receiver operating characteristic, AUC = $0.902, \mathrm{SE}=0.037,95 \% \mathrm{CI}: 0.830-$ $0.974, \mathrm{p}<0.001$.

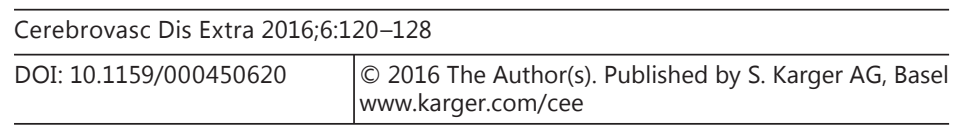

Pagram et al.: Peripheral Immune Cell Counts and Advanced Imaging as Biomarkers of Stroke Outcome
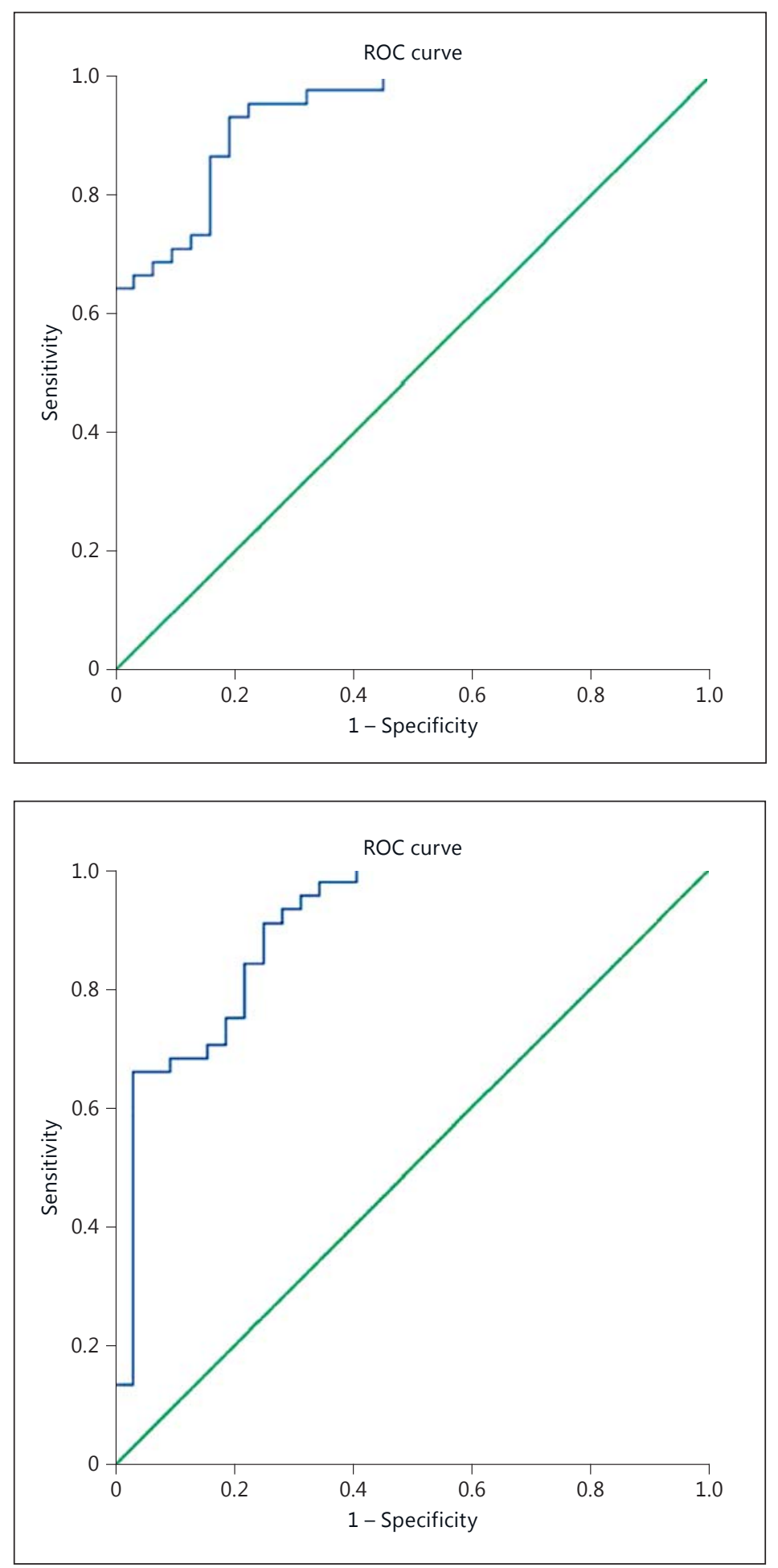

triggering a greater proportional increase in counts. Thus, we cannot be conclusive about a fully independent effect of the early neutrophilia on the 90-day outcome. However, after adjustment for stroke severity and the 24-hour infarct volume, the neutrophil count remained predictive of functional outcome at 90 days. Prior studies have also found a relationship between lymphocytopenia and poststroke infections leading to poor patient outcomes. This 
Pagram et al.: Peripheral Immune Cell Counts and Advanced Imaging as Biomarkers of Stroke Outcome

Table 3. Inclusion and exclusion criteria for human anti-neutrophil therapy trials, dosage and effect

\begin{tabular}{|c|c|c|c|c|c|}
\hline Phase III trial & Treatment & Inclusion criteria & Exclusion criteria & Dosage & Result \\
\hline $\begin{array}{l}\text { Enlimomab } \\
\text { (EAST) }\end{array}$ & $\begin{array}{l}\text { Anti-ICAM-1 } \\
\text { antibody }\end{array}$ & $\begin{array}{l}\text { Acute ischemic stroke } \\
\text { Enrolment within } 6 \mathrm{~h} \text { of } \\
\text { stroke onset } \\
\text { No contraindications to } \\
\text { treatment }\end{array}$ & $\begin{array}{l}\text { Information not } \\
\text { available }\end{array}$ & $\begin{array}{l}\text { First dose within } \\
6 \mathrm{~h} \text { of stroke onset } \\
\text { Repeated doses given } \\
\text { every } 24 \mathrm{~h} \text { for a total } \\
\text { of } 5 \text { Patients assigned } \\
\text { a variable fixed-dose } \\
\text { regimen }\end{array}$ & $\begin{array}{l}\text { Increased } \\
\text { mortality, } \\
\text { increased } \\
\text { infection } \\
\text { compared } \\
\text { to placebo }\end{array}$ \\
\hline $\begin{array}{l}\text { UK-279,276, } \\
\text { ASTIN variable } \\
\text { dose trial }\end{array}$ & $\begin{array}{l}\text { Neutrophil } \\
\text { (CD18, CD11b) } \\
\text { inhibitor factor }\end{array}$ & $\begin{array}{l}\text { Acute ischemic stroke } \\
\text { Previous independence } \\
\text { Age }>50 \text { years } \\
\text { Presenting with acute stroke } \\
\text { within } 6 \text { h of onset } \\
\text { Baseline Stroke Severity } \\
\text { Scale } 10-40 \\
\text { Alteplase permitted }\end{array}$ & $\begin{array}{l}\text { Impaired consciousness } \\
\text { Premenopause } \\
\text { Fixed-eye deviation with } \\
\text { hemiplegia } \\
\text { Seizure since stroke onset } \\
\text { Temperature }>38^{\circ} \mathrm{C} \\
\text { Concurrent infection }\end{array}$ & $\begin{array}{l}\text { Single (variable, in } \\
\text { ASTIN; fixed, in } \\
\text { UK-279,276) dose } \\
\text { administered } \\
\text { intravenously over a } \\
\text { period of } 15 \text { min } \\
\text { during hospital } \\
\text { admission }\end{array}$ & $\begin{array}{l}\text { No } \\
\text { treatment } \\
\text { effect }\end{array}$ \\
\hline $\begin{array}{l}\text { Hu23F2G } \\
\text { (LeukArrest) }\end{array}$ & $\begin{array}{l}\text { Anti-CD18 } \\
\text { antibody }\end{array}$ & $\begin{array}{l}\text { Acute ischemic stroke } \\
\text { Enrolment within } 10 \mathrm{~h} \text { of } \\
\text { stroke onset } \\
\text { Alteplase permitted } \\
\text { No contraindications to } \\
\text { treatment }\end{array}$ & $\begin{array}{l}\text { Information not } \\
\text { available }\end{array}$ & $\begin{array}{l}\text { Single dose within } \\
10 \mathrm{~h} \text { of stroke onset } \\
\text { Second dose } 60 \mathrm{~h} \\
\text { later }\end{array}$ & $\begin{array}{l}\text { No } \\
\text { treatment } \\
\text { effect } \\
\text { Halted early }\end{array}$ \\
\hline
\end{tabular}

trend was not observed in our study; however, this analysis did not measure poststroke infections and as such is not a fitting comparator [17].

All patients in this cohort presented within $4.5 \mathrm{~h}$ of onset and were alteplase treated, so the 'acute draw' is indeed representative of a very early time point. Reperfusion was also associated with higher neutrophil counts, though only at 7 days after stroke. Although reperfusion is a desirable outcome, it also leads to the increased production of ROS by CNS cells [18]. ROS triggers microglia to upregulate the production of inflammatory cytokines and so increases levels of neutrophil chemoattractant and contributes to the volume of inflammatory positive feedback after stroke. Further, reperfusion allows neutrophils to be recruited to the site of infarction by adhesion molecules in the microvasculature [19]. Given the enhanced reperfusion seen with alteplase treatment, it could be hypothesized that a neutrophil-modulating agent would potentially be of greater clinical value in more severe strokes where residual infarction persists despite reperfusion.

An association between the peripheral neutrophil count and stroke lesion volume has been observed previously [14]. Our results suggest that this relationship is limited to infarcted core tissue rather than penumbral tissue and that neutrophil levels are probably more associated with the extent of tissue necrosis. This phenomenon is not limited to brain tissue; cardiac allografts undergo necrosis and are rejected more rapidly in the presence of an environment with a high neutrophil and a low insulin-like growth factor-gamma (a T-cell product) count [20]. As rapid responders to stroke, neutrophils contribute to monocyte recruitment into CNS cells [21] and also participate in phagocytosis, as well as being phenotypically and functionally dependent upon chemokine and cytokine concentrations (tumor necrosis factoralpha and interferon-gamma) [22]. After stroke, the antibacterial actions of neutrophils and monocytes are subsumed to phagocytic activity [23], thus priming them for the removal of necrotic CNS tissue rather than combating peripheral infection, potentially also contributing to the depressed immune responses and infections observed after ischemia. A prior study also identified higher NLR to be a maker of mortality and function in patients with intra- 
Pagram et al.: Peripheral Immune Cell Counts and Advanced Imaging as Biomarkers of Stroke Outcome

cerebral hemorrhage [24]. The relationship between higher neutrophil counts and poor outcomes as well as increased NLR and functional outcome in hemorrhage patients may suggest that heightened immune responses are a reliable marker for disease severity and subsequent patient outcome [25]. Alternatively, early inflammation may be a driver of poor outcomes by limiting the regenerative capacities of infarcted tissue or tissue adjacent to free blood as in hemorrhages. The order or influence of inflammation on patient outcome requires further study to identify if targeted immune modulation will alter patient outcomes.

Our results may help to explain why past immunomodulatory trials targeting neutrophils (Enlimomab, LeukArrest and ASTIN) may have failed (table 3) [5-7]. Typically, a general reference to differences between human and mouse physiology is frequently cited, although it is unclear which difference, exactly, is to blame [5, 8]. Humans and rodents do indeed have vastly different cerebral vasculature and anatomy [12], in addition to different immunological profiles and features. Mice have a much smaller proportion of blood neutrophils, for example (10-25\% neutrophils; 75-90\% lymphocytes) compared to humans (50-70\% neutrophils, 30-50\% lymphocytes), which translates to NLRs of 0.1-0.3 versus 1.0-2.3 [26]. In some pathways, these cells also have differential expression patterns between the species, though how this translates into function is not yet understood. In recovery, susceptibility to poststroke infection varies even between mouse strains [27]. However, the problem with translation in this case may be in selecting human patients with disease characteristics that resemble those of the successful mouse model. Stroke in the laboratory is induced within the middle cerebral artery, commonly models transient ischemia and represents a relatively severe stroke. Conversely, these human trials (Enlimomab, ASTIN and LeukArrest) failed to differentiate between stroke subtypes, stroke severity and whether the patient had reperfused or not and thus may have inadvertently recruited a relatively mild cohort by comparison to the laboratory models.

The limitations of this study is its retrospective nature where the precise time of blood draws are unknown within $24 \mathrm{~h}$, and unknown with respect to the time of imaging acquisition. In addition, an influence of unmeasured confounding factors on functional outcome cannot be excluded.

In conclusion, we have observed a significant relationship between stroke severity and immune response after stroke that may contribute to patient outcomes. Past clinical trials have been unsophisticated and selected all patients rather than only those who may have more to benefit from neutrophil modulation therapy.

\section{Disclosure Statement}

The authors have no conflicts of interest to disclose.

\section{References}

$>1$ Jickling GC, Liu D, Ander BP, et al: Targeting neutrophils in ischemic stroke: translational insights from experimental studies. J Cereb Blood Flow Metab 2015;35:888-901.

$\longrightarrow 2$ Doll DN, Barr TL, Simpkins JW: Cytokines: their role in stroke and potential use as biomarkers and therapeutic targets. Aging Dis 2014;5:294-306.

-3 Segel GB, Halterman MW, Lichtman MA: The paradox of the neutrophil's role in tissue injury. J Leukoc Biol 2011;89:359-372.

4 Kumar AD, Boehme AK, Siegler JE, et al: Leukocytosis in patients with neurologic deterioration after acute ischemic stroke is associated with poor outcomes. J Stroke Cerebrovasc Dis 2013;22:e111-e117.

5 Macrez R, Ali C, Toutirais 0 , et al: Stroke and the immune system: from pathophysiology to new therapeutic strategies. Lancet Neurol 2011;10:471-480. 
Pagram et al.: Peripheral Immune Cell Counts and Advanced Imaging as Biomarkers of Stroke Outcome

6 Kwan J, Pickering RM, Kunkel D, et al: Impact of stroke-associated infection on long-term survival: a cohort study. J Neurol Neurosurg Psychiatry 2013;84:297-304.

7 Krams M, Lees KR, Hacke W, et al: Acute stroke therapy by inhibition of Neutrophils (ASTIN): an adaptive dose-response study of UK-279,276 in acute ischemic stroke. Stroke 2003;34:2543-2548.

$\checkmark 8$ Becker KJ: Anti-leukocyte antibodies: LeukArrest (Hu23F2G) and Enlimomab (R6.5) in acute stroke. Curr Med Res Opin 2008;18(suppl 2):s18-s22.

-9 Enlimomab Acute Stroke Trial Investigators: Use of anti-ICAM-1 therapy in ischemic stroke: results of the Enlimomab Acute Stroke Trial. Neurology 2001;57:1428-1434.

10 Jiang N, Moyle M, Soule HR, Rote WE, Chopp M: Neutrophil inhibitory factor is neuroprotective after focal ischemia in rats. Ann Neurol 1995;38:935-942.

11 Zhang L, Zhang ZG, Zhang RL, et al: Effects of a selective CD11b/CD18 antagonist and recombinant human tissue plasminogen activator treatment alone and in combination in a rat embolic model of stroke. Stroke 2003;34:1790-1795.

12 Dirnagl U, Iadecola C, Moskowitz MA: Pathobiology of ischaemic stroke: an integrated view. Trends Neurosci 1999;22:391-397.

13 Jin R, Yang G, Li G: Inflammatory mechanisms in ischemic stroke: role of inflammatory cells. J Leukoc Biol 2010;87:779-789.

14 Buck BH, et al: Early neutrophilia is associated with volume of ischemic tissue in acute stroke. Stroke 2008; 39:355-360.

15 Bivard A, Levi C, Spratt N, et al: Perfusion CT in acute stroke: a comprehensive analysis of infarct and penumbra. Radiology 2013;267:543-550.

16 Bivard A, Spratt N, Levi C, et al: Perfusion computer tomography: imaging and clinical validation in acute ischaemic stroke. Brain 2011;134:3408-3416.

17 Tokgoz S, Kayrak M, Akpinar Z, Seyithanoğlu A, Güney F, Yürüten B: Neutrophil lymphocyte ratio as a predictor of stroke. J Stroke Cerebrovasc Dis 2013;22:1169-1174.

18 Wang Q, Tang XN, Yenari MA: The inflammatory response in stroke. J Neuroimmunol 2007;184:53-68.

$\checkmark 19$ Prestigiacomo CJ, Kim SC, Connolly ES Jr, et al: CD18-mediated neutrophil recruitment contributes to the pathogenesis of reperfused but not nonreperfused stroke. Stroke 1999;30:1110-1117.

20 Miura M, El-Sawy T, Fairchild RL: Neutrophils mediate parenchymal tissue necrosis and accelerate the rejection of complete major histocompatibility complex-disparate cardiac allografts in the absence of interferon. Am J Pathol 2003;162:509-519.

21 Soehnlein 0, Lindbom L, Weber C: Mechanisms underlying neutrophil-mediated monocyte recruitment. Blood 2009;114:4613-4623.

22 Livingston DH, Appel SH, Sonnenfeld G, Malangoni MA: The effect of tumor necrosis factor-alpha and interferon-gamma on neutrophil function. J Surg Res 1989;46:322-326.

23 Ruhnau J, Schulze K, Gaida B, et al: Stroke alters respiratory burst in neutrophils and monocytes. Stroke 2014; 45:794-800.

24 Lattanzi S, Cagnetti C, Provinciali L, Silvestrini M: Neutrophil-to-lymphocyte ratio predicts the outcome of acute intracerebral hemorrhage. Stroke 2016;47:1654-1657.

25 Wang F, Hu S, Ding Y, Ju X, Wang L, Lu Q, Wu X: Neutrophil-to-lymphocyte ratio and 30-day mortality in patients with acute intracerebral hemorrhage. J Stroke Cerebrovasc Dis 2016;25:182-187.

26 Mestas J, Hughes CC: Of mice and not men: differences between mouse and human immunology. J Immunol 2004;172:2731-2738.

-27 Schulte-Herbrüggen O, Klehmet J, Quarcoo D, et al: Mouse strains differ in their susceptibility to poststroke infections. Neuroimmunomodulation 2006;13:13-18. 